\title{
Translating the Idea of the eGovernment One-Stop-Shop in Indonesia
}

\author{
Fathul Wahid \\ Department of Informatics, Universitas Islam Indonesia, Yogyakarta, Indonesia \\ Department of Information Systems, University of Agder, Kristiansand, Norway \\ fathul.wahid@uii.ac.id
}

\begin{abstract}
This study aims to understand how the idea of an eGovernment onestop-shop (OSS) has been translated into a new setting. Since the beginning of 2000 , this idea has been implemented in a variety of ways by Indonesian local governments. Using an interpretive case study in the city of Yogyakarta, the study revealed that the specificity of each setting influences the translation process of the idea of OSS during its institutionalization. It also identified a set of editing rules used during the translation process. These include the editing rules concerning context (e.g., internal readiness); logic (e.g., corruption eradication); and formulation (e.g., standardized processes). The study also found that the idea translation was not a single round process.
\end{abstract}

Keywords: one-stop-shop, eGovernment, idea translation, editing rules, institutionalization, institutional theory, developing countries, Indonesia.

\section{Introduction}

In its 2010 survey, the Political and Economic Risk Consultancy named Indonesia as one of the Asia's most inefficient bureaucracies that downgraded the quality of public services and discouraged investment [1]. This was a general assessment and did not provide detailed insights. If we scrutinize the state of bureaucracy at the local government level (i.e., city/district), a different picture emerges. For example, the World Bank [2] placed the city of Yogyakarta fifth in a list of the most efficient bureaucracies in terms of dealing with construction licenses among 183 economies in a global survey. In short, there is a huge discrepancy between different local governments in the quality of public services they provide $[2,3]$.

In order to improve the quality of public service and eradicate corruption, the government of Indonesia has taken various initiatives. At the local government level, one of these initiatives was translated into the establishment of an eGovernment one-stopshop (OSS). In this paper, OSS refers to the licensing department that provides a variety of services (such as construction and nuisance licenses) to the public. With the help of information technology (IT), the OSS was designed to cut red tape, 'burdensome administrative rules and procedures' [4:385]. 
However, not all OSSs in Indonesia have successfully achieved their potential for providing a better public service and curbing corrupt practices [3, 5]. Despite this, some local governments have enjoyed benefits from the successful implementation of the initiative. The city of Yogyakarta is one of them. This study aims to explain how the idea of OSS is translated in the institutionalization process at the context of local government. It is also motivated by a lack of studies that pay attention to such the process in the eGovernment initiative implementation [6, 7]. Hence, the main research question addressed by this study is: how is the idea of an eGovernment one-stop shop translated during its institutionalization process? The concepts of idea translation introduced by the Scandinavian institutionalism are used to explain the process of OSS institutionalization [8].

\section{Theoretical Framework}

\section{1 eGovernment One-Stop-Shop}

The establishment of OSS that can be considered as an implementation of 'joined-up government' $[9,10]$, may provide four benefits: eliminating the contradictions and tensions between different policies, making better use of scarce resources, improving the flow of good ideas and synergy between different stakeholders, and creating seamless rather than fragmented services. In the context of developing countries, the establishment of OSS is very important in cutting red tape and eradicating corruption $[11,12]$. The use of IT can help to reduce hierarchical structures and streamline the process of filtering out unnecessary impediments to efficient operation [4].

However, there are two inherent problems in this regard: a problem of coordination and a problem of integration and organization [13]. The former involves encouraging the agencies involved to work on broadly the same agenda, while the latter concerns the problem of how to align structures, incentives, and cultures to fit interorganizational tasks. Both of these are institutional problems. Previous studies argue that eGovernment will not achieve its potential without institutional change $[14,15]$.

Thus, in the context of Indonesia, the OSS has not yet really been able to provide effective online services. The citizens may get information, downloadable forms, and trace the status of an application from a website, but they cannot send the application online. In order to do so they have to visit the OSS physically to hand in applications and to make payments. In this context, we may consider the OSS as an eGovernment 'official' intermediary ${ }^{1}$ that helps citizens to get the public services they need. The role of intermediaries in providing eGovernment services in the context of developing countries is very influential [16].

\footnotetext{
${ }^{1}$ This term is used to differentiate between 'official' and 'unofficial' intermediaries. OSS is a manifestation of the former, while the latter are often not immune from corrupt practices (i.e., petty bribery). A survey conducted in Indonesia found that $48 \%$ of license applicants used the 'unofficial' intermediaries (i.e., local government staffs), and the use of such intermediaries increased the licensing costs by $58 \%$, despite the fact that this speeded up the process [3].
} 


\subsection{Idea Translation}

The concepts of idea translation originated from the Scandinavian institutional research can be said to "primarily come to highlight the dynamic aspect of circulating ideas; how and why ideas become wide-spread, how they are translated as they flow and with what organization consequences" [17:219]. Answers to these questions are needed to explain the process of translation of an idea in a certain setting. An organization does not operate in a vacuum, and an idea that is picked up can be adopted and incorporated into organizational practice. When an idea is adopted, it does not always work as planned and in many cases it can then be decoupled from ongoing activities of organization [18]. In order to work in its new setting, the idea requires a process of translation [19].

The translation process is described by Czarniawska and Joerges [20] in four stages: idea, object, action and institution. In a particular context, organizational actors select an idea among a collection of circulating ideas. The circulating ideas are disembedded from their original setting, before being reembedded into a new setting [20]. Once an idea is chosen, it will be subsequently transformed into an object. The objectification process makes the idea tangible. The easiest way to objectify ideas is to turn them into linguistic artefacts, such as labels and metaphors [20]. An idea can then be translated into an object (e.g. a prototype, text, model, perceptions, a concept) and can then be realised. Thus, an object becomes translated into an action. Finally, it may emerge as an institution if the action is regularly repeated over time and therefore becomes taken for granted.

However, the process of translation of an idea is in fact constrained by the editing rules which are often implicitly inherent within an organization [17]. In general the editing rules concern three factors: context, logic, and formulation [19]. Different settings may follow a variable set of idea editing rules. Ideas may be contextualized to consider aspects of time, space, and scale. New types of logic or explanations can be accepted; and/or be formulated as, e.g., a prototype to attract attention. The idea translation process is depicted schematically in Fig. 1.

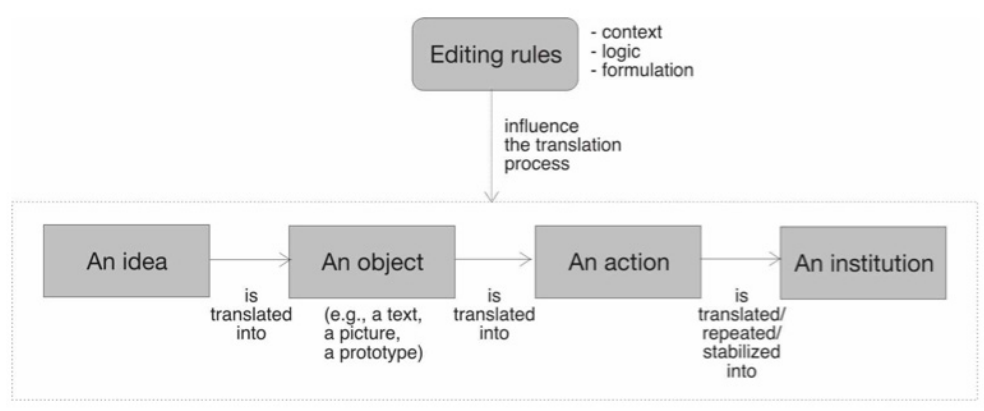

Fig. 1. The process of idea translation (adopted from [20]) 


\section{$3 \quad$ Research Method}

This case study is interpretative in nature. In choosing this approach, "our knowledge of reality is gained only through social constructions such as language, consciousness, shared meanings, documents, tools, and other artefacts" [21:69]. A case study is appropriate since the problem under investigation is practice-based, the experiences of the actors are important and the context of action is critical [22].

Data were collected mainly through interviews. Interviews were carried out with a variety of key players with OSS and/or eGovernment implementation at various levels. The interviewees were the mayor of the city of Yogyakarta, four heads/vice-heads of offices, three heads of divisions and one administrator. The snowball method was used to select the interviewees.

Eight interviews were conducted, most of which were recorded. Each interview lasted 30 to 60 minutes. The interviews were conducted between July and August 2011. To ensure the validity of the data [23], additional data were also collected from written documents/reports and field observations. The concepts of idea translation were used as templates when coding the data, and temporal bracketing as sensemaking strategy [24] was used in the data analysis.

\section{$4 \quad$ Findings}

\subsection{OSS as a Unit with a Limited Authority: 2000-2001}

The OSS in Yogyakarta can be traced back to 2000, when the local government decided to establish a one-roof service unit (Unit Pelayanan Terpadu Satu Atap [UPTSA]) to response the national regulation. This was the origin of the idea of the OSS. However, the regulation did not provide a comprehensive guide on how the OSS should be established.

At that time, UPTSA acted as a front office counter for 12 services that received the applications, whereby the mechanism to process the applications was similar to those that existed before its establishment. As a unit, UPTSA had no authority to approve the applications, but passed them on to the technical department that had the authority to issue the licenses. Thus, in the process of getting a license, the burdensome bureaucracy continued, although with some subtle improvements. A number of specific problems had to be coped with, such as the state of internal readiness. One informant asserted that:

"At that time, there was a lack of political will both from the mayor and the heads of departments. ... [There was] no independent budget allocation and no independent institution. We were not ready for that time."

The status of UPTSA also made smooth coordination with other departments difficult, as there was lack of integration between them.

A momentum emerged when a new mayor was elected in 2001. Before taking on the position, the mayor had been a successful businessman. He was interested on 
UPTSA, since he had experienced difficulties in the past when dealing with burdensome bureaucracy. The new mayor showed his political will to improve UPTSA. A comprehensive evaluation was carried out, involving all departments as part of the preparation process. The former head of UPTSA stated that:

"So, in 2001, we identified the authorities of all departments and simplified them. ... We identified which the licenses that could be integrated into the licensing department. Some of the licenses were very specific such as those for medical doctors and nurses. These kinds of licenses were still the authority of the respective technical departments."

\subsection{OSS as a Unit with a Higher Authority: 2002-2005}

Based on a set of recommendations from a comprehensive evaluation, some improvements were made. Among the problems identified at that time was the lack of a smooth flow of service provision, the need to assign employees to tasks effectively, to appoint a coordinator for UPTSA, and to improve the supporting facilities. In 2002, the mayor re-launched UPTSA. This re-launching initiative created a new momentum. One informant asserted that:

"In January 2002, supporting facilities of the UPTSA office were improved. ... UPTSA was then re-launched on March 4, 2002 by the mayor."

Since then, UPTSA has had its own budget. At that time the status of the officers who worked for it was still attached to the departments they had originated from. However, UPTSA included the possibility of coordinating the processing of the applications. Thus, the problems of coordination and integration were partly solved.

In 2003, a Government Regulation (Peraturan Pemerintah) No. 8/2003 concerning Guidelines for Local Government Organization was enacted. This national regulation made a comprehensive reorganization of all local government agencies possible. The existence of power interplay between actors was apparent at this stage. After an evaluation process, it was agreed that UPTSA should become a definitive government agency in the near future. The former head of UPTSA stated:

"When there was a new regulation from the national government, we did not take it for granted. ... We had to think holistically about organizational structure, personnel, budgeting, and authority. Taking away the authority [from a department] was not easy."

It was agreed to promote the status of UPTSA from a unit into a department (dinas), which legally would have a higher authority. The decision was was also a result of the idea translation process. At that time, the mayor showed his political leadership, by asking all the heads of department who did not agree with the decision to express their opinion. As one informant stated:

"The mayor invited all the heads of department involved. ... The mayor asked whom did not agree with the idea [of establishing an OSS as a department] to sign a statement on a paper bearing IDR 6,000 duty stamp. No one did it." 
There was also a shift in the role of IT in supporting licensing services. As one informant asserted:

"In 2000, the information technology section was just a supporting unit. ... But after making an organizational evaluation, the section became a core section. It happened in 2003."

Starting from 2003, several information systems (IS) were developed to support application processing. The use of IS helped to standardize the application process. Since that time, the application forms have been available online and a call center has been opened to provide information and to collect input and complaints from the citizens. A continuous evaluation procedure asked all the applicants to fill in a questionnaire to assess the quality of service from various points of view.

In 2004 the OSS initiative then received more impetus when the national government of Indonesia asked all government agencies to improve the quality of public service delivery, through Presidential Instruction No. 5/2004, as part of an effort to eradicate corruption. Then, the corruption eradication became institutional logic behind the establishment of OSS. The former head of OSS stated that:

"What we restructured at that time was not the licensing department, but all the departments. We identified what processes should be carried out by which department. No one complained, since we did not know to what department we would be assigned to."

\subsection{OSS as a Department: 2006-Present}

After going through an intricate process, at the end of 2005, through a local regulation (Peraturan Daerah) the mayor promoted the status of UPTSA as a unit to become a department. By using this new status, the Licensing Department (Dinas Perizinan) had the authority to process and to approve/disapprove applications. The department at that time had the responsibility for 35 types of licenses, while 24 other licenses were still being processed by the Health Department, due to their technical nature.

From the beginning, one of the main challenges was a new culture building, since the officers came from various departments. The (former) head of OSS cultivated the values of togetherness among the officers. It took around six months to build this new culture. In addition to the corruption eradication logic, there were also other institutional logics behind the OSS establishment and its development, from public services to internal process improvement. As one informant stated:

"The licensing department was established to improve the public services. We were on the public's side; the procedures were simplified. But, after the department was running, then I realized that the local government itself enjoyed the most advantages; including time efficiency, more controllable processing times, cost reductions and energy efficiency. No need to spend energy on coordination between the departments, since we were integrated."

The problems of integration and coordination were thus largely solved at this stage. To provide a better service, in 2007 a new organizational structure was adopted. Some procedures were simplified. In 2008 the number of licenses was reduced from 35 to 
29. Some technical licenses, however, such as license for a medical doctor, were still under the authority of the related technical departments.

Since 2007, the licensing department obtained recognition from various national and international institutions. Such recognition included an Investment Award in 2007 and 2008 from the Investment Coordinating Board (Badan Koordinasi Penanaman Modal [BKPM]) and the Service Excellence Award in 2008 from the Ministry for the Empowerment of State Apparatus. In 2010, Yogyakarta was named as the fifth most efficient bureaucracy in dealing with construction licenses among 183 surveyed economies [2]. In 2011 it obtained an ISO 9001:2008 certificate for quality assurance.

\section{Discussion}

This discussion focused on from answering the research questions set at the outset: how is the idea of eGovernment one-stop shop translated during its institutionalization process? In doing so, the four-stage idea translation process [20] was central.

This study found that the process of idea translation was not one-way. This study revealed that the idea of OSS has been translated three times (in 2000, 2002, and 2006). Here, the object (i.e., the concept of OSS) has been evaluated through the process of shaping and are being shaped by everyday practices (i.e., action and/or institution). This finding provided new insights and a theoretical contribution to the concept of idea translation that seemed to be simplified as a one-way translation process [cf. 20]. Fig. 2 depicts the contextualized process of idea translation.

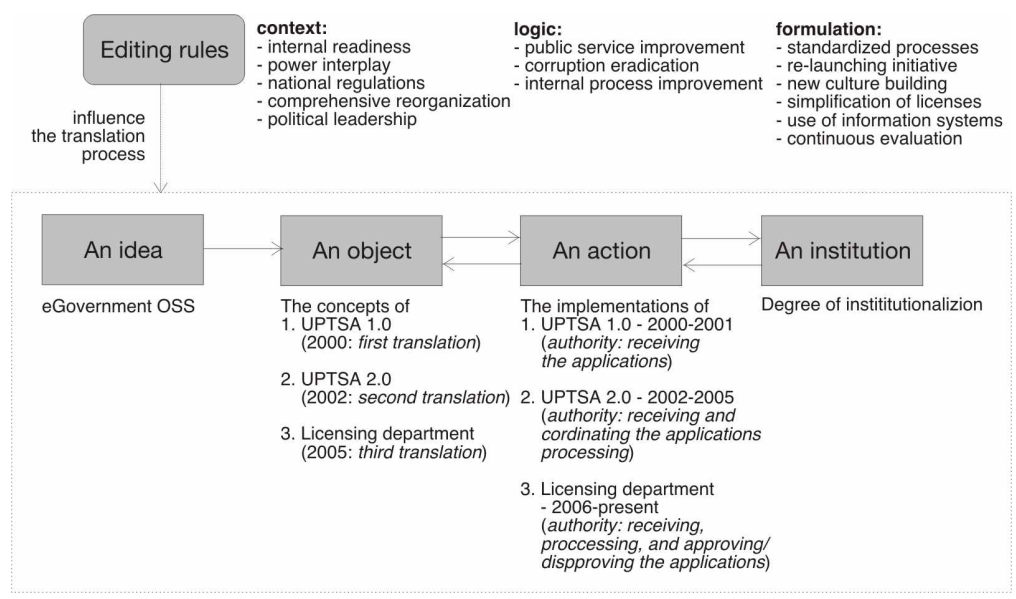

Fig. 2. The translation process of the OSS idea

Based on the presentation of the findings, several editing rules were identified during the process of idea translation (marked by a bold typeface in the Findings section) (see Fig 2.). Although the idea of OSS came from the national government, it did not provide detailed guidelines as to how an OSS should be 
established. It is necessary to ask why no such guidelines were provided by the national government. Detailed guidelines can have both a negative and a positive impact. In considering the specificity of each local government, imposing detailed guidelines might be misleading and make localization impossible. However, for local governments with limited exposure to external knowledge and/or with many competing institutional logics within their organisations, such guidelines would be very useful. Otherwise, the idea could be self-defeating [25].

In 2000, the idea of OSS was translated into an object (i.e., the concept of UPTSA $1.0^{2}$ ) and then into an action (its implementation). At that time, the concept was not well developed, since there were problems of integration and coordination. UPTSA 1.0 as a unit had only limited authority. At this stage, the authority of OSS was only to receive the application (see Fig. 3(a)). A lack of political will was identified as one of main challenges at that time. Due to these problems of integration and coordination [13], the first idea translation failed to become institutionalized.

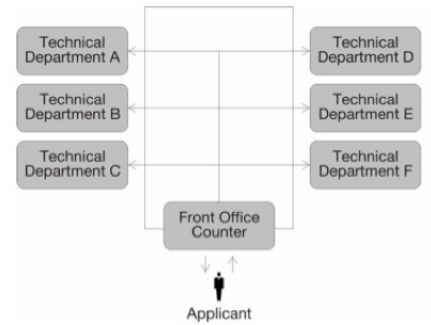

(a)

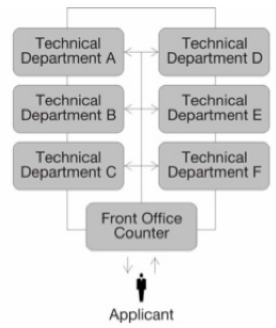

(b)

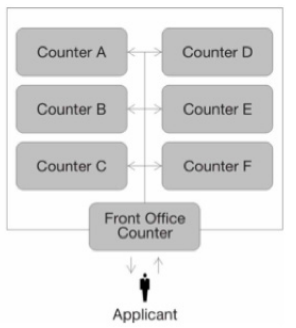

(c)

Fig. 3. Levels of OSS authority in Yogyakarta: (a) as a unit (2000-2001) - receiving; (b) as a unit (2002-2005) - receiving and coordinating; (c) as a department (2006-present) - receiving, processing, and approving. Note: The visual presentation was inspired by Steer [3].

The second attempt to translate the idea of OSS was carried out in 2002, when UPTSA 1.0 was re-launched as UPTSA 2.0. An evaluation report made at the beginning 2002 was the new translation object. The first translation was then corrected by improving the integration and coordination process between the involved departments. Since then, OSS has had a coordinating authority to process the application, in addition to just receiving it (see Fig. 3(b)). The problems of integration and coordination were partly solved. UPTSA 2.0 began to achieve a momentum towards becoming institutionalized by applying more standardized practices, supported by an improved IT infrastructure. However, there was still a need to streamline the application processing hindered by the limited authority of OSS.

At the third attempt, after carrying out comprehensive evaluation and preparation by the end of 2005, the idea of OSS was translated into a concept of a more integrated and a better-coordinated service provision. In 2006, UPTSA 2.0 became a licensing department with a higher authority (see Fig. 3(c)). This new status as a department

\footnotetext{
${ }^{2}$ The term 'UPTSA 1.0' is used to differentiate it from 'UPTSA 2.0' after a re-launching in
} 2002 . 
largely solved both the problems of integration and coordination. The new practice became routine through typification process where certain forms of actions came to be associated with certain classes of actors [26]. This process helped the licensing department become institutionalized.

\section{Conclusion}

This paper has presented the process of how an idea of OSS was translated in a specific setting. The concept of idea translation from Scandinavian institutionalism was used as a focus. This study has made two main contributions. Firstly, it has offered an explanation of how the same idea of OSS can be translated differently when it is implemented in a new setting. A new application of the concept of idea translation in the context of eGovernment studies can bring about a better understanding of the process of localization or local improvisation of an eGovernment initiative. A set of editing rules concerning context, logic, and formulation was also identified to explain this process. Secondly, theoretically, the study has offered empirical evidence to incorporate the multiple-round idea translation process.

This study was not without its limitations. It focused on a single case. Including various cases of the translation process of the idea of OSS, may reveal a more comprehensive picture of the possible process and its editing rules. However, as an interpretive study, the findings are generalized to theoretical concepts rather than the population [27]. As such we can make inferences about the concept of idea translation. It would also be interesting for future research to identify the circumstances in which the one-way or multiple-round translation process could be made more favourable.

\section{References}

1. Anonymous: India, Indonesia 'worst for red tape'. The Sydney Morning Herald (2010)

2. The World Bank and The International Finance Corporation: Doing Business in Indonesia 2010. The World Bank and The International Finance Corporation, Washington (2010)

3. Steer, L.: Business Licensing and One Stop Shops in Indonesia. The Asia Foundation (2006)

4. Welch, E.W., Pandey, S.K.: E-Government and bureaucracy: Toward a better understanding of intranet implementation and its effect on red tape. Journal of Public Administration Research and Theory 17, 379-404 (2006)

5. The Asia Foundation: Making Sense of Business Licensing in Indonesia: A Review of Business Licensing Policy and Survey of One Stop Shop Service Centers. The Asia Foundation, San Francisco (2007)

6. Wahid, F.: The Current State of Research on eGovernment in Developing Countries: A Literature Review. In: Scholl, H.J., Janssen, M., Wimmer, M.A., Moe, C.E., Flak, L.S. (eds.) EGOV 2012. LNCS, vol. 7443, pp. 1-12. Springer, Heidelberg (2012)

7. Wahid, F.: Themes of research on eGovernment in developing countries: Current map and future roadmap. In: Proceedings of the 46th Hawaii International Conference on System Sciences (HICSS 2013) (2013) 
8. Czarniawska, B., Sevón, G.: Introduction. In: Czarniawska, B., Sevón, G. (eds.) Translating Organizational Change, pp. 1-12. Walter de Gruyter, Berlin (1996)

9. Pollitt, C.: Joined-up government: A survey. Political Studies Review 1, 34-49 (2003)

10. Persson, A., Goldkuhl, G.: Joined-Up E-Government - Needs and Options in Local Governments. In: Wimmer, M.A., Scholl, H.J., Janssen, M., Traunmüller, R. (eds.) EGOV 2009. LNCS, vol. 5693, pp. 76-87. Springer, Heidelberg (2009)

11. Guriev, S.: Red tape and corruption. Journal of Development Economics 73, 489-504 (2004)

12. Bardhan, P.: Corruption and development: a review of issues. Journal of Economic Literature 35, 1320-1347 (1997)

13. Mulgan, G.: Joined up government: Past, present and future. In: Bogdanor, V. (ed.) Joinedup Government. Oxford University Press, Oxford (2005)

14. Avgerou, C.: IT and organizational change: An institutionalist perspective. Information Technology and People 13, 234-262 (2000)

15. Furuholt, B., Wahid, F.: E-government challenges and the role of political leadership in Indonesia: The case of Sragen. In: Proceedings of the 41st Hawaii International Conference on System Sciences (HICSS 2008) (2008)

16. Sein, M.K., Furuholt, B.: Intermediaries: Bridges across the digital divide. Information Technologies for Development 18, 332-344 (2012)

17. Sahlin, K., Wedlin, L.: Circulating ideas: Imitation, translating and editing. In: Greenwood, R., Oliver, C., Suddaby, R., Sahlin, K. (eds.) The SAGE Handbook of Organizational Institutionalism, pp. 218-242. Sage, Los Angeles (2008)

18. Meyer, J.W., Rowan, B.: Institutional organizations: Formal structure as myth and ceremony. American Journal of Sociology 83, 340-463 (1977)

19. Sahlin-Andersson, K.: Imitating by editing success: The construction of organizational fields. In: Czarnlawska, B., Sevon, G. (eds.) Translating Organizational Change, pp. 6992. Walter de Gruyter, Berlin (1996)

20. Czarniawska, B., Joerges, B.: Travel of ideas. In: Czarniawska, B., Sevón, G. (eds.) Translating Organizational Change, pp. 13-48. Walter de Gruyter, Berlin (1996)

21. Klein, H.K., Myers, M.D.: A set of principles for conducting and evaluating interpretive field studies in information systems. MIS Quarterly 23, 67-93 (1999)

22. Benbasat, I., Goldstein, D.K., Mead, M.: The case research strategy in studies of information systems. MIS Quarterly 11, 369-386 (1987)

23. Yin, R.K.: Case Study Research: Design and Methods. Sage, California (2009)

24. Langley, A.: Strategies for theorizing from process data. Academy of Management Review 24, 691-710 (1999)

25. Zafarullah, H.: Adminsitrative reform in Bangladesh: An unfinished agenda. In: Farazmand, A. (ed.) Administrative Reform in Developing Nations, pp. 49-72. Praeger Publishers, Westport (2002)

26. Scott, W.R.: Institutions and Organizations: Ideas and Interest. Sage, Thousand Oaks (2008)

27. Lee, A.S., Baskerville, R.L.: Generalizing generalizability in information systems research. Information Systems Research 14, 221-243 (2003) 